\title{
Effects of ethanol on the expression of caveolin-1 in HepG2 cells
}

\author{
YING WANG, JING TONG, BING CHANG, BAI-FANG WANG, DAI ZHANG and BING-YUAN WANG \\ Department of Gastroenterology, The First Affiliated Hospital of China Medical University, \\ Shenyang, Liaoning 110001, P.R. China
}

Received November 30, 2013; Accepted June 9, 2014

DOI: $10.3892 / \mathrm{mmr} .2015 .3296$

\begin{abstract}
This study aimed to investigate the effects of ethanol on the expression of caveolin-1 (CAV-1) in HepG2 hepatocarcinoma cells. Ethanol-treated HepG2 cells were investigated using the in vitro model to determine whether ethanol can influence the expression of CAV-1. Cell viability was measured using the colorimetric 3-(4,5-dimethylthiazol-2-yl)-2,5-diphenyltetrazolium bromide (MTT) and lactate dehydrogenase (LDH) assays. Expression of CAV-1 was detected using western blot analysis. Quantitative PCR (qPCR) was used to determine CAV-1 mRNA levels. The distribution of CAV-1 in HepG2 cells was analyzed using immunofluorescence. The MTT assay results revealed that cell viability was not altered at ethanol concentrations of $<1.0 \%$, while ethanol concentrations $>1.0 \%$ caused cell shedding, but not cell fragmentation. Western blot analysis showed significant differences in the levels of CAV-1 expression between the control group and the $1.0 \%$ ethanol-treated group at 6,12 and $24 \mathrm{~h}$ (all $\mathrm{P}<0.05)$. qPCR showed significant differences in the expression levels of caveolin-1 mRNA between the control group and the $1.0 \%$ ethanol-treated group at $6 \mathrm{~h}, 12 \mathrm{~h}$ and $24 \mathrm{~h}$ (all $\mathrm{P}<0.05)$. Immunofluorescence demonstrated that CAV-1 was distributed discontinuously at the boundaries of HepG 2 cells. The results indicate that ethanol may increase the expression of CAV-1 in HepG2 cells.
\end{abstract}

\section{Introduction}

Caveolae are 50-100 $\mathrm{nm}$ omega-shaped membranes that represent a sub-compartment of the plasma membrane (1). Caveolin-1 (CAV-1) is the most researched among the three principal proteins in caveolae (CAV-1, -2 and -3) (1). CAV-1 is a $21-24 \mathrm{kDa}$ protein which has emerged as a plasma membrane organizer, sensor and protector that can respond to plasma membrane stress and remodel the extracellular

Correspondence to: Professor Bing-Yuan Wang, Department of Gastroenterology, The First Affiliated Hospital of China Medical University, 115 Nanjing Street, Heping, Shenyang, Liaoning 110001, P.R. China

E-mail: cmu1h_wby@126.com

Key words: ethanol, caveolin-1, HepG2 cells environment (2). The expression of CAV-1 is closely associated with its transcription through various signaling pathways that are mediated by a number of molecules, and it is widely expressed in numerous cell types, including fibroblasts, endothelial cells and epithelial cells $(3,4)$. Transcriptional control of gene expression is regulated by microRNAs (miRNAs), regulatory molecules that mediate effects by interacting with messenger RNA (mRNA) targets (5). Thus, CAV-1 mRNA, and the abundance of CAV-1 protein associated with it, can be considered a potential controller that subtly adjusts the proteome levels in transcriptional and translational repression despite a small number of targets $(1,2)$. Previous studies revealed that CAV-1 and its mRNA could be expressed in numerous types of human cancer, including breast, lung, prostate and renal cancers (6-9). A number of studies have also identified significant correlations between the expression of CAV-1 and its mRNA and liver carcinogenesis $(10,11)$.

Ethanol is an important factor in the pathogenesis of liver cancer. Metabolically, ethanol is first converted to acetaldehyde, an unstable molecule that generates reactive oxygen species (ROS) and can directly drive the onset of DNA damage and the DNA damage/repair response $(12,13)$. Generally, ethanol may be directly involved in hepatic cell injury through the induction of ROS following oxidative stress or by CAV-1 translocation to the lipid droplets, thereby affecting DNA methylation patterns and cell signaling pathways and resulting in increased liver iron deposition $(14,15)$. A previous study indicates that CAV-1 expression can be used as a new biomarker for monitoring oxidative stress induced by ethanol (16). However, whether ethanol can affect the expression of CAV-1 has not yet been reported. In the present study, ethanol-treated HepG2 cells were observed using the in vitro model to investigate the effects of ethanol on the expression of CAV-1.

\section{Materials and methods}

Chemicals and reagents. Unless otherwise noted, all chemicals were obtained from Sigma-Aldrich Chimie (Saint-Quentin Fallavier, France). Standard molecular biological techniques were applied. Rabbit monoclonal glyceraldehyde-3-phosphate dehydrogenase (GAPDH) antibody, rabbit anti-cav-1 and antiGAPDH antibodies and the CAV-1 $(1: 1,000)$ antibody were obtained from Santa Cruz Biotechnology, Inc. (Santa Cruz, CA, USA). TRIzol ${ }^{\circledR}$ reagent was purchased from Invitrogen ${ }^{\mathrm{TM}}$ (Life Technologies, Carlsbad, CA, USA). ReverTra Ace ${ }^{\circledR}$ qPCR 
RT kit and Thunderbird ${ }^{\mathrm{TM}} \mathrm{SYBR}^{\circledR}$ qPCR mix were obtained from Toyobo (Tokyo, Japan). Primers were designed by AlleleID6.01 (Premier Biosoft International, Palo Alto, CA, USA) and synthesized by Sangon Biotech Co. Ltd. (Shanghai, China). Total protein extraction kits were also purchased from Sangon Biotech Co. Ltd.

Culture of HepG2 cells. Human HepG2 hepatocarcinoma cells were obtained from American Type Culture Collection (Rockville, MD, USA). The HepG2 cells were routinely cultivated in Dulbecco's modified Eagle's medium (DMEM; Hyclone, Logan, UT, USA), which consisted of $10 \%$ fetal calf serum (FCS; Hyclone), glucose $(4.5 \mathrm{mg} / \mathrm{ml})$, glutamine $(4 \mathrm{~mm})$, and antibiotics $(50 \mathrm{U} / \mathrm{ml}$ penicillin and $50 \mathrm{U} / \mathrm{ml}$ streptomycin; Sigma, St. Louis, MO, USA). Prior to the experiment, cells were incubated at $37^{\circ} \mathrm{C}$ in a humidified atmosphere of $95 \%$ air and $5 \% \mathrm{CO}_{2}$, and the medium was changed every other day.

HepG2 cells were divided into two groups, one of which was plated onto 6-well plates in DMEM with $10 \%$ fetal bovine serum. After overnight attachment, HepG2 cells were incubated for up to $12 \mathrm{~h}$ with $0.5,1.0,2.5,5.0$ and $7.5 \%$ ethanol or without ethanol and in the presence or absence of $5 \mathrm{~mol} / \mathrm{l}$ 4-methylpyrazole, $10 \mathrm{~mol} / \mathrm{l}$ diallyl sulfide, or $100 \mathrm{~mol} / \mathrm{l}$ uric acid. Unless otherwise indicated, the medium was exposed to the stated ethanol concentrations for $24 \mathrm{~h}$ prior to analysis.

Cell viability assay. To determine cell viability the 3-(4,5-dimethylthiazol-2-yl)-2,5-diphenyltetrazolium bromide (MTT) assays were used. The MTT relies on a reductive coloring reagent and dehydrogenase in a viable cell to determine cell viability with a colorimetric method (17). The MTT assay is the best known method for determining mitochondrial dehydrogenase (SDH) activities in living cells (18). With this method, MTT is reduced to a purple formazan by nicotinamide-adenine dinucleotide. However, MTT formazan is insoluble in water, and it forms purple needle-shaped crystals in the cells. Therefore, prior to measuring absorbance, an organic solvent is required to solubilize the crystals. SDH activity was detected after $3 \mathrm{~h}$ incubation in culture medium without serum, containing $250 \mu \mathrm{g} / \mathrm{ml}$ MTT. After removing the culture medium, formazan crystals were dissolved in dimethyl sulphoxide. The absorbance intensity of the purple solution that was produced was spectrophotometrically measured by a Fusion $^{\text {TM }}$ microplate reader (Packard Bioscience, Meriden, CT, USA) with a reference wavelength of $535 \mathrm{~nm}$.

Cell viability was also assessed by measuring the release of lactate dehydrogenase (LDH) in the culture medium and cell lysate using a LDH kit (Roche Diagnostics, Mannheim, Germany). LDH is a soluble cytosolic enzyme present in the majority of eukaryotic cells, and upon cell death it is released into the culture medium as a result of damage to the plasma membrane (19). The increase of LDH activity in the culture supernatant is proportional to the number of lysed cells (20). LDH participates in a coupled reaction, converting yellow tetrazolium salt into a red, formazan-class dye, which was measured by absorbance at $485 \mathrm{~nm}$. A LDH standard curve $(0-3,000 \mathrm{mU} / \mathrm{ml})$ was used for quantifying enzyme activity.

Western blot analysis. The HepG2 cells were washed three times without calcium and magnesium using Dulbecco's phosphate-buffered saline (DPBS; Dulbecco's Formula Modified; ICN Biochemicals, England), which contained $0.1 \mathrm{mM}$ ethylenediamine tetraacetic acid (EDTA). Subsequently, the HepG2 cells were homogenized in $1 \mathrm{ml}$ lysis buffer A (2 mm EDTA, $10 \mathrm{~mm}$ ethylene glycol tetraacetic acid, $0.4 \% \mathrm{NaF}, 20 \mathrm{~mm}$ Tris-HCL, protease inhibitor cocktail, phosphatase inhibitor $1 \% \operatorname{Triton}^{\circledR} \mathrm{X}-100, \mathrm{pH} 7.5$ ) at $4^{\circ} \mathrm{C}$. Samples were centrifuged at $14,000 \mathrm{x}$ g for $30 \mathrm{~min}$ and the supernatant was decanted to a separate tube and collected as a soluble fraction. Buffer A (150 $\mu \mathrm{l})$ with $1 \%$ sodium dodecyl sulfate (SDS) at $4^{\circ} \mathrm{C}$ was then added to the pellet. The pellet was disrupted using an ultrasonic crusher. The samples were then centrifuged at $14,000 \mathrm{xg}$ for $30 \mathrm{~min}$ at $4^{\circ} \mathrm{C}$, as previously described. The supernatant was collected as an insoluble fraction. Equal amounts of proteins (40-50 $\mu \mathrm{g})$ were separated by SDS-polyacrylamide gel electrophoresis and processed for immunoblotting with antibodies for CAV-1 (diluted 1:1,000). The blots were inhibited with 5\% nonfat dry milk in Trisbuffered saline containing TBS $(20 \mathrm{mM}$ Tris and $137 \mathrm{mM}$ $\mathrm{NaCl} ; \mathrm{pH} 7.5$ ) and $0.3 \%$ Tween 20 (TBS-T) for $3 \mathrm{~h}$ at $25^{\circ} \mathrm{C}$ and then incubated with antibodies for CAV-1 $(1: 1,000)$ for $16 \mathrm{~h}$ at $4^{\circ} \mathrm{C}$. All protein bands were scanned using ChemiImager 5500 V2.03 software (Alpha Innotech, San Leandro, CA, USA), and integrated density values were calculated with a computerized image analysis system (FluorChem 2.0; Bio-Rad, Hercules, CA, USA) and normalized to that of $\beta$-actin.

Quantitative PCR ( $q P C R$ ). Total RNA was extracted from cells using the RNA Mini kit (Ambion, Paisley, UK) according to the manufacturer's instructions. Genes of interest were amplified from $2 \mathrm{mg}$ DNase I-treated total RNAs with Thunderbird ${ }^{\mathrm{TM}}$ reverse transcriptase (Toyobo) and a random primer. The primers used for qPCR are listed in Table I (21). For qPCR, transcripts were quantified by Applied Biosystems 7300 Real-Time PCR system (Life Technologies) and Thunderbird ${ }^{\mathrm{TM}} \mathrm{SYBR}^{\circledR}{ }_{\mathrm{qPCR}}$ mix. The qPCR reactions were performed by adding $10 \mu \mathrm{l}$ solution of clone pC (10-fold dilutions of an initial stock solution concentration of $0.0056 \mathrm{fmol} \mathrm{pC/ \mu l)}$ to $1 \mu 1$ test DNA (0.1$0.5 \mathrm{fmol}$ total $\mathrm{mtDNA} / \mu \mathrm{l}$ ) in a standard $100 \mu \mathrm{l} \mathrm{PCR}$ reaction [10 mM Tris-HCl, $50 \mathrm{mM} \mathrm{KCI,} 2 \mathrm{mM} \mathrm{MgC12,} 400 \mu \mathrm{M}$ each of dATP, dCTP, dGTP, TTP (Pharmacia Biotech, Picastaway, NJ, USA), 100 pmol of each primer, 2.5 units of Taq polymerase (Perkin-Elmer, Waltham, MA, USA) and $10 \mathrm{UCi}$ of [a-32P]dATP (Amersham, Arlington Heights, IL, USA)]. The PCR reaction was run on a Biocycler (IBI; Bios Corp., New Haven, CT, USA) at $94^{\circ} \mathrm{C}$ for $20 \mathrm{sec}, 65^{\circ} \mathrm{C}$ for $20 \mathrm{sec}$ and $72^{\circ} \mathrm{C}$ for $20 \mathrm{sec}$ for $25 \mathrm{cycles}$. The extension of the last cycle was at $72^{\circ} \mathrm{C}$ for $10 \mathrm{~min}$. Following the last cycle, the DNA was denatured at $95^{\circ} \mathrm{C}$ for $10 \mathrm{~min}$ and then cooled to room temperature. Subsequently, $10 \mu \mathrm{l}$ PCR product was digested with 0.5 units Sspl overnight at $37^{\circ} \mathrm{C}$. The digested DNA fragments were separated by electrophoresis on a $12 \%$ non-denaturing polyacrylamide gel (29:1 acrylamide:bis) and the labelled fragments were visualized by autoradiography on X-ray films [Ray Chem Medica (P) Ltd., Delhi, India] of the vacuum-dried gels. These experiments were performed in triplicate and independently repeated at least three times. GAPDH was used as an internal control for gene expression analysis. 
Table I. Quantitative PCR primer sequences.

\begin{tabular}{llcr}
\hline Gene & PCR primer sequences & Cycle number & PCR products (bp) \\
\hline CAV-1 & 5'-CGCGACCCTAAACACCTCAA-3' & 40 & 254 \\
& 5'-GCCGTCAAAACTGTGTGTCC-3' & & 605 \\
GAPDH & 5'-ACCACAGTCCATGCCATCAC-3' & 40 & \\
& 5'-TCCACCACCCTGTTGCTGTA-3' & &
\end{tabular}

CAV-1, calveolin-1; GAPDH, glyceraldehyde-3-phosphate dehydrogenase.

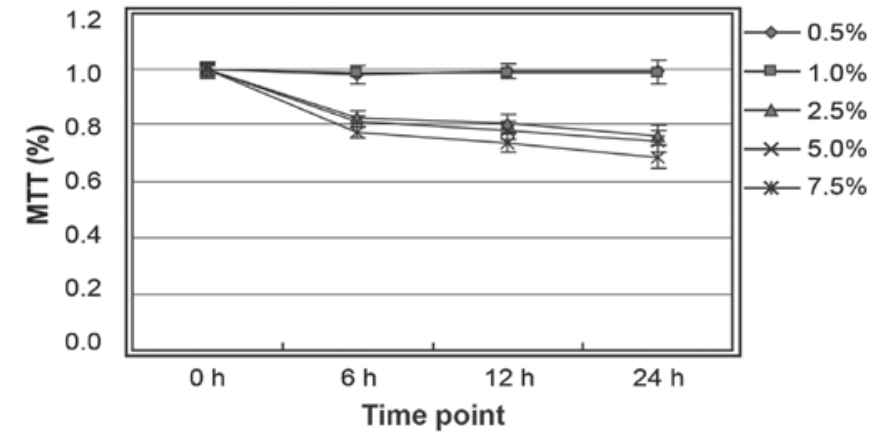

Figure 1. Effect of ethanol on the viability of HepG2 cells by using the colorimetric 3-(4,5-dimethylthiazol-2-yl)-2,5-diphenyltetrazolium bromide (MTT) assay. The HepG2 cells were treated with ethanol at different concentrations $(0.5,1.0,2.5,5.0$ and $7.5 \%)$ for 6,12 or $24 \mathrm{~h}$.

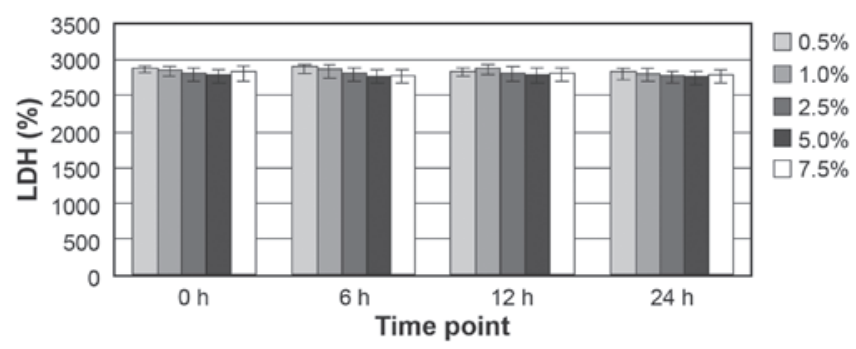

Figure 2. Cell viability was assessed by measuring the released cytosolic enzyme lactate dehydrogenase (LDH) in the culture medium and the cell lysate. The HepG2 cells were treated with ethanol at different concentrations $(0.5,1.0,2.5,5.0$ and $7.5 \%)$ for 6,12 or $24 \mathrm{~h}$.

Immunofluorescence. The HepG2 cell monolayers grown on glass coverslips were fixed with $4 \%$ paraformaldehyde and permeabilized with $0.5 \%$ Triton ${ }^{\circledR}$ X-100. Following blocking with $2 \%$ bovine serum albumin in PBS, the cells were incubated with rabbit anti-CAV-1 (diluted 1:50) to visualize the distribution of CAV-1. The glass slides were analyzed using BX-50-FLA immunofluorescence microscopy (Olympus, Tokyo, Japan).

Statistical analysis. Experiments were repeated at least three times. Continuous variables were expressed as the mean \pm standard deviation. Categorical data were presented as frequencies and percentages. Differences between the groups were compared using the two-tailed, non-paired Student's t-test or one-way analysis of variance for continuous variables, where appropriate. Comparisons of categorical variables between the groups were performed using the $\chi^{2}$ test. All tests

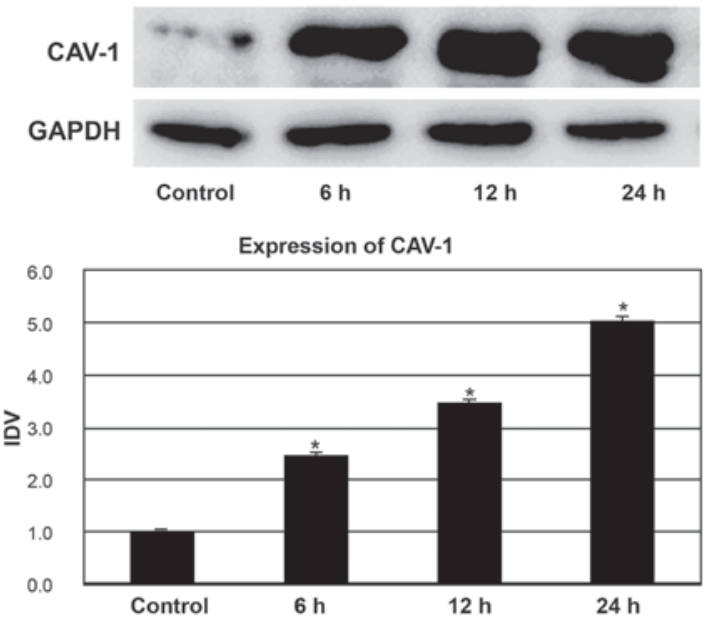

Figure 3. Effect of $1.0 \%$ ethanol on the expression of caveolin-1 (CAV-1) in HepG2 cells using western blot analysis with glyceraldehyde 3-phosphate dehydrogenase (GAPDH) as a control. The HepG2 cells in the ethanol group were treated with $1.0 \%$ ethanol for 6,12 , or $24 \mathrm{~h}$. ${ }^{*} \mathrm{P}<0.05$ compared with the control group.

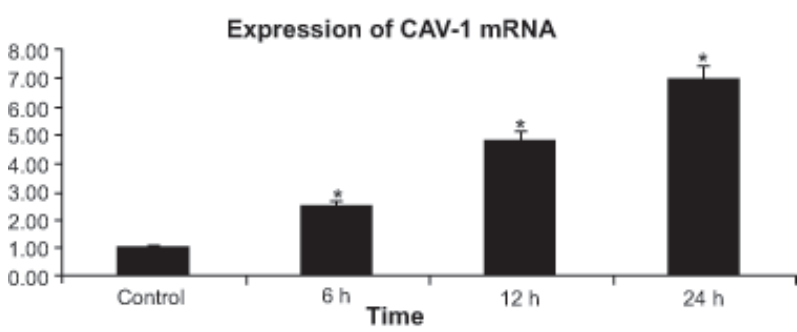

Figure 4. Effect of $1.0 \%$ ethanol on the expression of caveolin-1 (CAV-1) mRNA in HepG2 cells using quantitative PCR. The HepG2 cells in the ethanol group were treated with $1.0 \%$ ethanol for 6,12 or $24 \mathrm{~h}$. " $\mathrm{P}<0.05$ compared with the control group.

of statistical significance were two-sided, and $\mathrm{P}<0.05$ was considered to indicate a statistically significant difference. The statistical analyses were calculated with SPSS 17.0 (SPSS, Inc., Chicago, IL, USA).

\section{Results}

Effect of ethanol on HepG2 cell viability. The HepG2 cells were treated with ethanol at different concentrations $(0.5$, $1.0,2.5,5.0$ and $7.5 \%$ ) for 6,12 or $24 \mathrm{~h}$. MTT assay showed that cell viability was not altered at ethanol concentrations of $\leq 1.0 \%$ (Fig. 1). LDH assay indicated that $\geq 7.5 \%$ ethanol did 

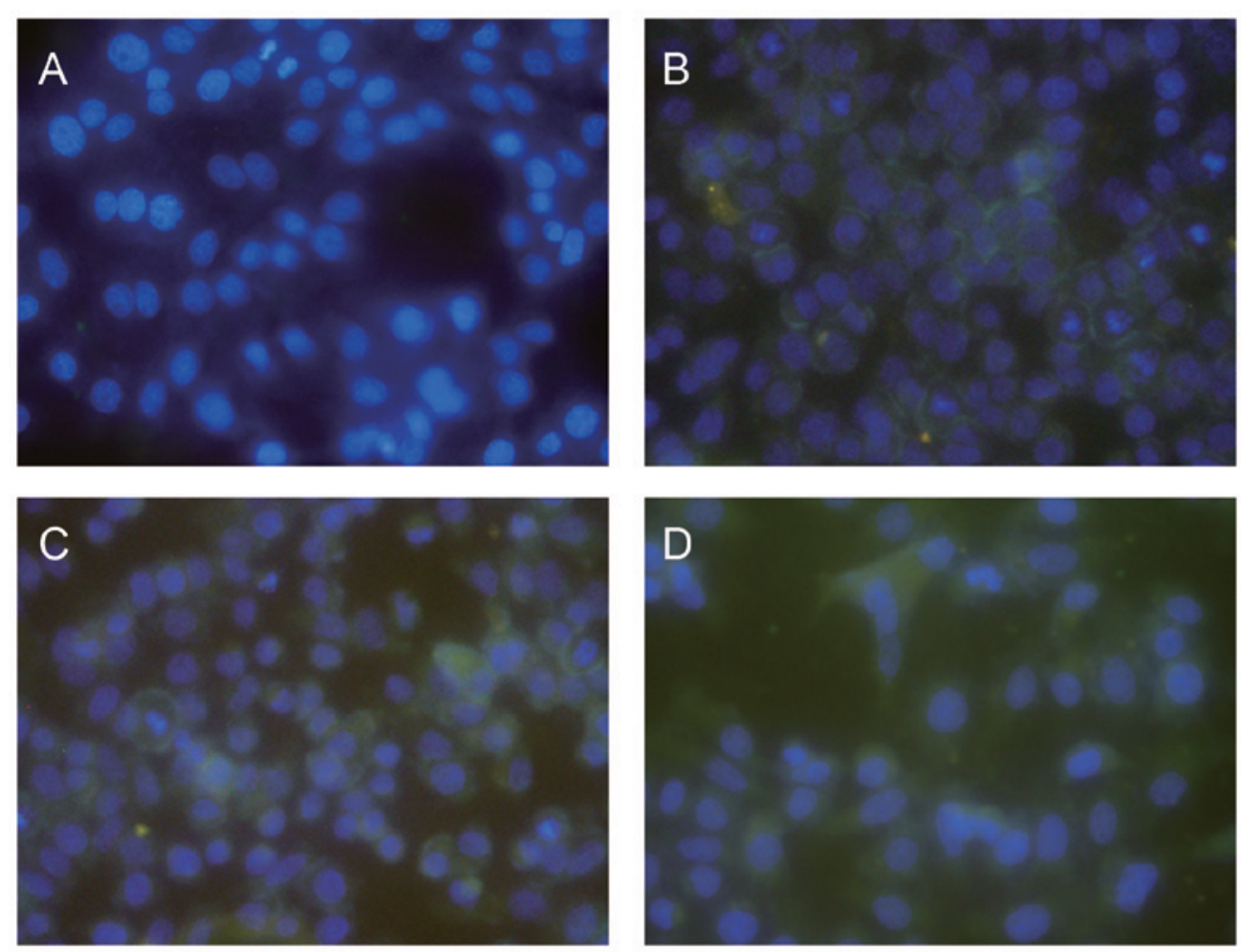

Figure 5. Immunofluoresence (magnification, x400) showed the distribution of caveolin-1 in HepG2 cells following treatment with 1.0\% ethanol. (A) HepG2 cells in the control group; HepG2 cells treated with 1.0\% ethanol for (B) $6 \mathrm{~h}$; (C) $12 \mathrm{~h}$; and (D) $24 \mathrm{~h}$.

not increase the release of the cytosolic enzyme LDH into the medium (Fig. 2). Ethanol concentrations $>1.0 \%$ caused cell shedding, but not cell fragmentation. At an ethanol concentration of $7.5 \%$, the ratio of shedding cells was up to $32.16 \pm 2.28 \%$. Therefore, subsequent experiments were conducted using an ethanol concentration of $1.0 \%$.

Effect of ethanol on the expression of CAV-1. The HepG2 cells in the ethanol group were treated with $1 \%$ ethanol for 6,12 , and 24 h. As shown in Fig. 3, the expression levels of CAV-1 showed an increase after treatment with $1.0 \%$ ethanol. Western blot analysis showed significant differences in CAV-1 expression between the control group and the $1.0 \%$ ethanol-treated group at 6,12 and $24 \mathrm{~h}$ (all $\mathrm{P}<0.05)$. After treatment with $1.0 \%$ ethanol, the expression levels of CAV-1 mRNA in HepG2 cells also exhibited an increasing trend (Fig. 4). Significant differences in the expression levels of CAV-1 mRNA were identified between the control group and the $1.0 \%$ ethanol-treated group at 6, 12 and $24 \mathrm{~h}($ all $\mathrm{P}<0.05)$.

Distribution of CAV-1 in HepG2 cells. The distribution of CAV-1 in HepG2 cells was assessed by immunofluorescent microscopy. CAV-1 was distributed discontinuously in the boundaries of HepG2 cells (Fig. 5).

\section{Discussion}

CAV-1 is the chief structural protein of caveolae and is a plasma membrane protector organizer and sensor that can respond to plasma membrane stresses and remodel the extracellular environment (22). Numerous studies suggest that the involvement of
CAV-1 in a variety of cellular processes has a significant effect on the internalization of pathogens, cholesterol homeostasis, transendothelial vesicular transport, integration of signaling pathways, and regulation of cell growth and proliferation (23-28). Generally, downregulation of $\mathrm{CAV}-1$ can release and activate signaling molecules and promote cell transformation and proliferation during the first stage of tumorigenesis, which may encourage rapid tumor growth and advanced metastasis $(29,30)$. On the contrary, the overexpression of CAV-1 has been demonstrated to be closely correlated with the expression of classic markers of tumor progression (Ki-67 and p53), and can mediate filopodia formation, increase proliferation and protect against apoptosis, which may enhance the invasive ability of certain adenocarcinoma cells $(31,32)$. Numerous previous studies have revealed that $\mathrm{CAV}-1$ expression is downregulated in many forms of cancer $(6,7,33,34)$. Even though the molecular mechanism of this controversial function of CAV-1 remains to be elucidated, these findings imply that CAV-1 may act as a tumor suppressor gene and a metastasis-promoting gene (35).

In the present study, MTT and LDH assays showed that cell viability was not altered at ethanol concentrations of $\leq 1.0 \%$, while ethanol concentrations $>1.0 \%$ led to cell shedding. Based on these results, $1.0 \%$ ethanol was defined as the maximum concentration at which ethanol has no significant influence on HepG2 cell viability and molecular structure. The results of the current study demonstrate that $1.0 \%$ ethanol may result in a significant increase in the levels of CAV-1 expression in HepG2 cells at 6,12 and $24 \mathrm{~h}$. This result may be due to proteolysis caused by increased ROS following oxidative stress, or to CAV-1 translocation to the lipid droplets, considering its role in lipogenesis. A previous study indicated that this increase in CAV-1 
may be associated with the alteration of mitochondrial permeability, a primary cause of the swelling. However, there are other factors involved in the regulation of mitochondrial permeability, and their role cannot be completely dismissed (36). The present study also demonstrated that the expression of CAV-1 mRNA in HepG2 cells exhibited an increasing trend following treatment with $1.0 \%$ ethanol, which supports the theory that ethanol affects the expression of CAV-1 and its mRNA. Metabolically, ethanol is first converted to acetaldehyde, which is an unstable molecule that generates ROS and can directly drive the onset of DNA-damage and the DNA-damage/repair response $(12,13)$. Ethanol may be involved directly in the injury of hepatic cells by the effect of CAV-1 translocation to the lipid droplets on DNA methylation patterns and cell signaling pathways $(14,15)$. Wang and Abdel-Rahman (16) presented evidence that ethanol induces metabolic changes in the tumor microenvironment and fuels tumor cell growth via oxidative mitochondrial metabolism. They also demonstrate that caveolin-1 protein expression can be effectively used as a new biomarker to monitor oxidative stress induced by ethanol.

In conclusion, this study indicates that ethanol may increase the expression levels of CAV-1 in HepG2 cells.

\section{Acknowledgements}

The authors would like to thank all of their colleagues working in the Department of Gastroenterology, The First Affiliated Hospital of China Medical University. This study was funded by the Department of Science and Technology Project of Liaoning Province (2011225015) and the Scientific Research of the First Hospital of China Medical University (fsfh1313).

\section{References}

1. Fu Y, Hoang A, Escher G, et al: Expression of caveolin-1 enhances cholesterol efflux in hepatic cells. J Biol Chem 279: 14140-14146, 2004.

2. Hendrickson DG, Hogan DJ, McCullough HL, et al: Concordant regulation of translation and $\mathrm{mRNA}$ abundance for hundreds of targets of a human microRNA. Plos Biol 7: e1000238, 2009.

3. Yang XY, Huang CC, Kan QM, et al: Calcium regulates caveolin-1 expression at the transcriptional level. Biochem Biophys Res Commun 426: 334-341, 2012

4. Sotgia F, Martinez-Outschoorn UE, Howell A, et al: Caveolin-1 and cancer metabolism in the tumor microenvironment: markers, models, and mechanisms. Annu Rev Pathol 7: 423-467, 2012

5. Khraiwesh B, Arif MA, Seumel GI, et al: Transcriptional control of gene expression by microRNAs. Cell 140: 111-122, 2010.

6. Sloan EK, Ciocca DR, Pouliot N, et al: Stromal cell expression of caveolin-1 predicts outcome in breast cancer. Am J Pathol 174 2035-2043, 2009.

7. Chen HL, Fan LF, Gao J, Ouyang JP and Zhang YX: Differential expression and function of the caveolin-1 gene in non-small cell lung carcinoma. Oncol Rep 25: 359-366, 2011.

8. Thompson TC, Tahir SA, Li L, et al: The role of caveolin-1 in prostate cancer: clinical implications. Prostate Cancer Prostatic Dis 13: 6-11, 2010.

9. Yu S, Zhang L, Li N, et al: Caveolin-1 up-regulates ST6Gal-I to promote the adhesive capability of mouse hepatocarcinoma cells to fibronectin via FAK-mediated adhesion signaling. Biochem Biophys Res Commun 427: 506-512, 2012.

10. Meyer C, Dzieran J, Liu Y, et al: Distinct dedifferentiation processes affect caveolin-1 expression in hepatocytes. Cell Commun Signal 11: 6, 2013.

11. Tse EY, Ko FC, Tung EK, et al: Caveolin-1 overexpression is associated with hepatocellular carcinoma tumourigenesis and metastasis. J Pathol 226: 645-653, 2012.
12. Abraham J, Balbo S, Crabb D and Brooks PJ: Alcohol metabolism in human cells causes DNA damage and activates the Fanconi anemia-breast cancer susceptibility (FA-BRCA) DNA damage response network. Alcohol Clin Exp Res 35: 2113-2120, 2011.

13. Seitz HK and Stickel F: Acetaldehyde as an underestimated risk factor for cancer development: role of genetics in ethanol metabolism. Genes Nutr 5: 121-128, 2010.

14. Cederbaum AI, Lu Y and Wu D: Role of oxidative stress in alcohol-induced liver injury. Arch Toxicol 83: 519-548, 2009.

15. Vluggens A and Reddy JK: Nuclear receptors and transcription factors in the development of fatty liver disease. Curr Drug Metab 13: 1422-1435, 2012.

16. Wang $X$ and Abdel-Rahman AA: Effect of chronic ethanol administration on hepatic eNOS activity and its association with caveolin-1 and calmodulin in female rats. Am J Physiol Gastrointest Liver Physiol 289: G579-G585, 2005.

17. Denizot F and Lang R: Rapid colorimetric assay for cell growth and survival. Modifications to the tetrazolium dye procedure giving improved sensitivity and reliability. J Immunol Methods 89: 271-277, 1986.

18. Vega-Avila E and Pugsley MK: An overview of colorimetric assay methods used to assess survival or proliferation of mammalian cells. Proc West Pharmacol Soc 54: 10-14, 2011.

19. Smith SM, Wunder MB, Norris DA and Shellman YG: A simple protocol for using a LDH-based cytotoxicity assay to assess the effects of death and growth inhibition at the same time. Plos One 6: e26908, 2011.

20. Cummings BS, Wills LP and Schnellmann RG: Measurement of cell death in Mammalian cells. Curr Protoc Pharmacol Chapter 12: Unit 12.8, 2012.

21. Fuchs S, Hollins AJ, Laue M, et al: Differentiation of human alveolar epithelial cells in primary culture: morphological characterization and synthesis of caveolin-1 and surfactant protein-C. Cell Tissue Res 311: 31-45, 2003

22. Quest AF, Lobos-Gonzalez L, Nunez S, et al: The caveolin-1 connection to cell death and survival. Curr Mol Med 13: 266-281, 2013.

23. Chidlow JH Jr and Sessa WC: Caveolae, caveolins, and cavins: complex control of cellular signalling and inflammation. Cardiovasc Res 86: 219-225, 2010.

24. Garrean S, Gao XP, Brovkovych V, et al: Caveolin-1 regulates NF-kappaB activation and lung inflammatory response to sepsis induced by lipopolysaccharide. J Immunol 177: 4853-4860, 2006.

25. Razani B, Combs TP, Wang XB, et al: Caveolin-1-deficient mice are lean, resistant to diet-induced obesity, and show hypertriglyceridemia with adipocyte abnormalities. J Biol Chem 277: 8635-8647, 2002.

26. Yokomori H, Oda M, Yoshimura K, et al: Vascular endothelial growth factor increases fenestral permeability in hepatic sinusoidal endothelial cells. Liver Int 23: 467-475, 2003.

27. Giancotti FG: Complexity and specificity of integrin signalling. Nat Cell Biol 2: E13-E14, 2000.

28. Ten Dijke P, Goumans MJ, Itoh F and Itoh S: Regulation of cell proliferation by Smad proteins. J Cell Physiol 191: 1-16, 2002.

29. Wang S, Kan Q, Sun Y, et al: Caveolin-1 regulates neural differentiation of rat bone mesenchymal stem cells into neurons by modulating Notch signaling. Int J Dev Neurosci 31: 30-35, 2013.

30. Senetta R, Stella G, Pozzi E, et al: Caveolin-1 as a promoter of tumour spreading: when, how, where and why. J Cell Mol Med 17: 325-336, 2013.

31. Tanase CP, Dima S, Mihai M, et al: Caveolin-1 overexpression correlates with tumour progression markers in pancreatic ductal adenocarcinoma. J Mol Histol 40: 23-29, 2009.

32. Pancotti F, Roncuzzi L, Maggiolini M and Gasperi-Campani A: Caveolin-1 silencing arrests the proliferation of metastatic lung cancer cells through the inhibition of STAT3 signaling. Cell Signal 24: 1390-1397, 2012.

33. Han F and Zhu HG: Caveolin-1 regulating the invasion and expression of matrix metalloproteinase (MMPs) in pancreatic carcinoma cells. J Surg Res 159: 443-450, 2010.

34. Prinetti A, Aureli M,Illuzzi G, et al: GM3 synthase overexpression results in reduced cell motility and in caveolin-1 upregulation in human ovarian carcinoma cells. Glycobiology 20: 62-77, 2010.

35. Yeh D, Chen C, Sun MZ, et al: Caveolin-1 is an important factor for the metastasis and proliferation of human small cell lung cancer NCI-H446 cell. Anat Rec (Hoboken) 292: 1584-1592, 2009.

36. Mastrodonato M, Portincasa P, Mentino D, et al: Caveolin-1 and mitochondrial alterations in regenerating rat liver. Microsc Res Tech 75: 1026-1032, 2012. 